\title{
Spatial differences and multi-mechanism of carbon footprint based on GWR model in provincial China
}

\author{
WANG Shaojian ${ }^{1,2},{ }^{*}$ FANG Chuanglin ${ }^{1}$, MA Haitao ${ }^{1}$, WANG Yang ${ }^{3}$, QIN Jing ${ }^{1,2}$ \\ 1. Institute of Geographic Sciences and Natural Resources Research, CAS, Beijing 100101, China; \\ 2. University of Chinese Academy of Sciences, Beijing 100049, China; \\ 3. Guangzhou Institute of Geography, Guangzhou 510070, China
}

\begin{abstract}
Global warming has been one of the major concerns behind the world's high-speed economic growth. How to implement the coordinated development of the carbon footprint and the economy will be the core issue of the world's economic and social development, as well as the heated debate of the research at home and abroad in recent years. Based on the energy consumption, integrated with the "Top-Down" life cycle approach and geographically weighted regression (GWR) model, this paper analyzed the spatial differences and multi-mechanism of carbon footprint in provincial China in 2010. Firstly, this study calculated the amount of carbon footprint of each province using "Top-Down" life cycle approach and found that there were significant differences of carbon footprint and per capita carbon footprint in provincial China. The provinces with higher carbon footprint, mainly located in northern China, have large economic scales; the provinces with higher per capita carbon footprint are mainly distributed in central cities such as Beijing, Shanghai and energy-rich regions and heavy chemical bases. Secondly, with the aid of GIS and spatial analysis model (GWR model), this paper had unfolded that the expansion of economic scale is the main driver of the rapid growth of carbon footprint. The growth of population and urbanization also acted as promoting factors for the increase of the carbon footprint. Energy structure had no considerable promoting effect for the increase of the carbon footprint. Improving energy efficiency is the most important factor to inhibit the growing carbon footprint. Thirdly, developing low-carbon economies and low-carbon industries, as well as advocating low-carbon city construction and improving carbon efficiency would be the primary approaches to inhibit the rapid growth of carbon footprint. Moderately controlling the economic scale and population size would also be required to alleviate carbon footprint. Meanwhile, environmental protection and construction of low-carbon cities would evoke extensive attention in the process of urbanization.
\end{abstract}

Keywords: carbon footprint; spatial differences; multi-mechanism; GWR model; China

Received: 2013-05-07 Accepted: 2013-11-18

Foundation: National Natural Science Foundation of China, No.41371177; Major Program of National Social Science Foundation of China, No.13\&ZD027

Author: Wang Shaojian (1986-), PhD Candidate, specialized in land use and resources \& urban geography.

E-mail: 1987wangshaojian@163.com

"Corresponding author: Fang Chuanglin (1966-), Professor, specialized in land use and resources \& urban geography. E-mail: fangcl@igsnrr.ac.cn 


\section{Introduction}

Global warming has become an important issue in various fields all over the world (IPCC, 2008). Most scholars believe that the greenhouse effect exacerbating is one of the most important causes of global warming (Pierucci, 2009). And human activity is the main driving factor intensifying the greenhouse effect (Duro and Padilla, 2006). The increase of energy consumption and population, as well as rapid economic growth, causing global carbon emissions increased dramatically, are the very important driving forces of aggravating the trend of climate warming. Under this background, a lot of new concepts and policies, such as "low-carbon economy", "low carbon industry", "low carbon development", "low carbon life", emerge as the times require. How to control the carbon footprint growth has become a burning issue worldwide attracting considerable attention from policy makers and scholars (Liu et al., 2008; Fan et al., 2010; Shimada et al., 2007; Lee, 2011).

Carbon footprint, originated from ecological footprint concept, is the land area possessing biological productiveness, to maintain a certain population survival and economic development need or being able to absorb emissions from human waste (Wackernagel and Rees, 1996). Carbon footprint is generally recognized as the research method to cope with climate change and solve the quantitative evaluation of carbon emissions intensity at home and abroad. The oversea research about carbon footprint sprung up very early (Wiedmann, 2009; Jeffrey et al., 2007). Foreign scholars focus on the regional carbon emissions of developed countries and carbon footprint differences and do a lot of research and argument. Research scope mainly involves in Europe, America, Japan and other countries and regions (Casler and Rose, 1998; Chang and Lin, 1998; Soytasa et al., 2007; Janssens et al., 2003). Research scale includes global, national, regional and other scales, with an emphasis on national research scale (Piao et al., 2009; Hong, 2011). Research perspectives mainly refer to the contrast research about direct and indirect carbon footprint, as well as the study about productive and consumer carbon footprint (Kees and Kornelis, 1995; Kenny, 2009). The research evaluation methods are various, frequently covering input and output (IO), life cycle analysis (LCA), and the IPCC emissions calculation method, etc (Chang and Lin, 1998; Kenny and Gray, 2009; Druckman and Jackson, 2009). Abroad research on regional carbon footprint focus primarily involves carbon footprint impacting on regional environment and economic development, to explore the relationship between carbon emissions and economic growth. However, the dominant factors affecting carbon emissions are different according to the research of different scholars in different areas.

The development course of western developed countries shows that the rigid connection exists among economic development, energy demand and carbon emissions. The rapid growth of energy consumption plays a decisive role in the increase of carbon emissions (Liu and Liu, 2009; Liu et al., 2002). Since the reform and opening up, China's economic and social development has made remarkable achievements, but also paid a heavy resource and environmental cost (Wei et al., 2008). In order to explore the relationship between the carbon footprint and economic development, domestic studies began to involve in carbon footprint. The documents about carbon emissions and economic development at home can be divided into three categories. Firstly, according to Kuznets curve theory and studies of the 
relationship between carbon emissions and per capita GDP, the analysis mainly focuses on the existence of the inverted U-shaped curve and the inflexion point (Du et al., 2007; Lin and Jiang, 2009). Secondly, using the index decomposition method, the studies analyze the contributions of the factors, including the energy structure, energy efficiency, economic income, to carbon emissions (Xu et al., 2006). Lastly, adopting the associated patterns of industry-energy and energy-carbon emissions, researches mainly deal with the changes of the regional patterns of carbon emissions (Zhang, 2006). The studies not only contain the analysis of carbon footprint about the industry space at the national scale but also at the regional scale like Jiangsu, Shanghai, mainly analyze and evaluate the state of carbon footprint in different industries and regions, as well as quantitative researches of the impact of economic and social development on regional energy consumption carbon footprint (Shi et al., 2012; Zhao et al., 2010; Zhao et al., 2011; Zhu et al., 2009; Zhang and Shi, 2011). The above mentioned are based on the national macro-level study of carbon footprint impact on economic development and regional environment. However, publications on provincial level have rarely been studied. Since the reform and opening up, China has acknowledged the inevitable stage of uneven regional development. Preferential policies have allowed some regions to speed up economic growth and it is hoped that the benefits will trickle down to the lagged regions. This leads to the obviously increase of regional economic differences and the polarization phenomenon in quite a number of provinces of China. Developed areas also contain relatively backward areas. Based on such analysis, provincial China is the frontier of research on carbon footprint given its scale and data available. Therefore, studying spatial differences in carbon footprint among provinces in China is very meaningful.

In order to explore the carbon footprint in China with an emphasis on the multimechanism, this paper draws on a "Top-Down" life cycle and GWR model analytical framework proposed by Padgett et al. (2008) and Wei et al. (2011) to address the complexity of carbon footprint and economy in provincial China and synthesize its multiple driving forces. Firstly, following a "Top-Down" life cycle approach, we move beyond the traditional analysis to quantitatively calculate the amount of carbon footprint and per capita carbon footprint based on energy consumption in provincial China and geographically analyze the spatial differences. Secondly, based on GWR model, we primarily do the regression of some factors, as energy structure (dominant energy share of total energy consumption), energy efficiency (per unit GDP energy consumption), urbanization (level of urbanization), economy factor (per capita GDP) and population factor (population size). After using the GWR model, we obtain the primary and secondary influencing factors affecting the carbon footprint, and present the major means of inhibition the rapid growth of carbon footprint and necessary measures to ease the rapid growth of carbon footprint. This paper is organized as follows. The next section presents the data sources and methods. Then we start with analyzing the spatial differences of the total carbon footprint and per capita carbon footprint. This is followed by a detailed investigation of the multi-mechanism of carbon footprint among 30 provinces in China with GWR model. The paper concludes with major findings and policy implications. 


\section{Data and methods}

\subsection{Data sources}

The provincial economic and population data are collected from "China Statistical Yearbook" (China Statistics Press, 2011) and the statistical yearbook of each province. The carbon footprint analysis data, based on the 2010 input-output tables (IOTs), have been calculated in this paper. The data about carbon emission and its coefficient in sectors of each province are extracted from the corresponding province's energy balance table in Energy Statistical Yearbook (China Statistics Press, 2011). Specifically, by organizing each province's primary energy (including coal, oil and natural gas) consumption data firstly, then splitting each province's total energy consumption into the 60 departments according to the energy balance table and the input-output table about the final energy consumption of sectors, we get each sector's foil energy consumption. Furthermore, using the emission coefficient offered by IPCC, we transfer each province's foil energy consumption into each sector's carbon emission. Carbon emissions divided by the total output of various departments, direct carbon emission coefficient is obtained. In addition, combined with formula (10), the total carbon emission coefficient of divisions in each province is obtained. Due to the lack of relevant data in Tibet, Taiwan Province, Hong Kong and Macao Special Administrative Regions, all data sources and results in this paper did not include these areas.

\subsection{Calculation methods of carbon footprint}

Generally, calculating the total carbon footprint is impossible due to the large amount of data required and the fact that carbon dioxide can be produced by natural occurrences (Wright et al., 2011). For simplicity of calculating, it is often expressed in terms of the amount of carbon dioxide, or its equivalent of other greenhouse gas (GHGs), emitted. Therefore, this paper calculates carbon footprint in the form of carbon dioxide coming from energy consumption. Specifically, total carbon footprint can be measured by two methods, one is from the top to down (Top-Down) and another is from the bottom to up (Bottom-Up) (Padgett et al., 2008; MacMinn and Juanes, 2009; Shi et al., 2012). The Top-Down method is selected to calculate carbon emission of final demand induced by the life cycle based on the life cycle assessment method and the input-output analysis. The total carbon footprint of each province is calculated based on the corresponding province's input-output tables. In the input-output model, the formula of calculating the gross output of $\alpha$ th department is as follows (Shi et al., 2012):

$$
x_{\alpha}=\sum_{\beta=1}^{n} x_{\alpha \beta}+\omega_{\alpha}
$$

where $x_{\alpha}$ is the total output of the $\alpha$ th department; $x_{\alpha \beta}$ denotes the intermediate inputs from $\alpha$ department input to $\beta$ department; and $\omega_{\alpha}$ is the final demand as to $\alpha$ department's products.

$$
\text { direct input coefficient, } k_{\alpha \beta}, k_{\alpha \beta}=x_{\alpha \beta} / x_{\alpha}
$$

where $0<k_{\alpha \beta}<1$ is intermediate consumption from unit output of $\beta$ department to the product of $\alpha$ department.

Combined with formula (2), formula (1) can be written as: 


$$
x_{\alpha \beta}=\sum_{\beta=1}^{n} k_{\alpha \beta} x_{\beta}+\omega_{\alpha}
$$

expressed as matrix:

$$
X=K X+W
$$

where $X, K$ and $W$ represent total output matrix, intermediate input coefficient matrix and final demand matrix respectively.

$(I-K)$ is non-singular matrix and is also reversible due to the property of $K$. Therefore, the expression of formula (4) becomes:

$$
X=(I-K)^{-1} W
$$

where $(I-K)^{-1} W$ is the Leontief inverse matrix, donates complete demand of input sector by producing unit final production.

The provincial input-output tables are Import-competing model. Implicit assumption is that imported products have the same properties with the similar domestic products. They have a competitive relationship, can replace each other completely. Imported products as well as domestic products enter into the intermediate demand and final demand equally. Therefore, it is needed to exclude the impact of imports for Leontief inverse matrix and the final demand. Leontief inverse matrix expression after being processed is as follows:

$$
\bar{B}=\left[\overline{b_{\alpha \beta}}\right]=[I-(I-\overparen{M}) K]^{-1}
$$

The final demand after being processed can be written as:

$$
\bar{W}=\left[\overline{w_{\beta}}\right]=(I-\overparen{M}) W
$$

In order to associate with carbon emission and input-output model, direct carbon emission coefficient should be confirmed:

$$
E=\left(e_{\beta}\right), e_{\beta}=c_{\beta} / x_{\beta}
$$

where $E$ is the direct carbon emission coefficient matrix; $e_{\beta}$ is the direct carbon emission coefficient of $\beta$ department; $c_{\beta}$ is direct carbon emission of $\beta$ department; and $x_{\beta}$ is the output of $\beta$ department.

Complete carbon emission coefficient means carbon emission of unit output from products meeting the final demand in the entire life cycle. It can be obtained by direct carbon emission coefficient multiply Leontief inverse matrix:

$$
L=\left[l_{\beta}\right], l_{\beta}=\sum_{\alpha} e_{\alpha} \times \overline{b_{\alpha \beta}}
$$

Carbon footprint is deprived through multiplication of complete carbon emission coefficient $\left(l_{\beta}\right)$ and the final demand $\left(\overline{w_{\beta}}\right)$ :

$$
C=\left[\overline{c_{\beta}}\right], \quad c_{\beta}=l_{\beta} \times \overline{w_{\beta}}
$$

\subsection{Geographically Weighted Regression (GWR model)}

Multivariate regression analysis has been extensively applied in estimating the relationships among variables. It is used for modeling and analyzing a couple of variables, when the focus is on the relationship between a dependent variable and one or more independent variables. 
Generally, it has two main types of regression model; one is global multivariate regression model and another is local multivariate regression model. More specifically, a global multivariate regression model (including ordinary least squares, spatial error and spatial lag models) can investigate the average strength and significance of statistical relationships between independent and dependent variables with just one equation for all data (Gilbert and Chakraborty, 2010). However, it is difficult to obtain the satisfactory results by using global regression model analyzing spatial data. This is because the global model in fact has assumed the variables have homogeneity before analyzing the spatial data. And it may hide potentially significant local variations in the relationships. Geographically weighted regression (GWR) model embeds the data's spatial location into the regression parameter (Fotheringham et al., 2002; Wang et al., 2010). GWR estimates point parameter in sequence using local weighted ordinary least squares and the weights is the distance function of the geospatial location of the regression point to the geospatial location of other observation points. The changes of geospatial position parameter estimates along with the geospatial location can be used to detect the spatial relationships among variables very intuitive. The formula of GWR model in our study is similar to global regression models; however, the parameters vary with spatial location (Hu et al., 2012):

$$
\ln y_{i}=\beta_{i 0}+\beta_{i 1} x_{i 1}+\ldots+\beta_{i k} x_{i k}+\ldots \beta_{i 5} x_{i 5}+\varepsilon_{i}
$$

where $i=1, \ldots, 30$ denotes spatial location of provinces in China; $y_{i}$ is the dependent variable total carbon footprint of $s$ province; five independent variables $x_{i k}(k=1, \ldots, 5)$, including energy structure $(S)$, energy efficiency $(F)$, urbanization level $(U)$; economic factor $(R)$ and population factor $(P) ; \beta_{i k}$ are local regression parameters to be estimated; $\varepsilon_{i}$ is random error. Therefore every province (except Tibet and Taiwan) in our research has a set of specific parameters to reflect the relationships between carbon footprint and the five independent variables.

Besides parameter localization, spatial autocorrelation is imbedded in the GWR model. As we all know, spatial weight matrix is an important part in the GWR model (Brunsdon et al., 2000). It is very important to choose the appropriate spatial weight matrix. According to Tobler's first law of geography, everything is related to everything else, but near things are more related than distant things (Tobler, 1970). Therefore, neighboring provinces of the regression variable should obtain more attention than distant provinces when estimating the parameters of the regression variable. In our study we select a weight matrix to represent the relative importance between provinces. The weight value is a distance-decay function which is a Gaussian like "bell" shape function. The parameters are solved by the following matrix form, where $T$ is the matrix transpose operation (Hu et al., 2012).

$$
\overline{\beta_{i}}=\left(X^{T} W^{I} X\right)^{-1} X^{T} W_{i} y
$$

$W_{i}$ is a diagonal weighting matrix as follows:

$$
w_{i}=\operatorname{diag}\left(w_{i 1}, w_{i 2}, \cdots w_{i n}\right)=\left[\begin{array}{cccc}
w_{i 1} & 0 & \cdots & 0 \\
0 & w_{i 2} & 0 & 0 \\
\vdots & \vdots & \cdots & \vdots \\
0 & 0 & \cdots & w_{i n}
\end{array}\right]
$$

The bandwidth or neighbors for a variable to determine which nearby neighbors should be 
included in the matrix or to determine fixed distance using the selection of "bandwidth parameter". It is also very important in the application of GWR model because it controls the model's smoothness. Generally, each variable is very different from others. Provinces with low carbon footprint cover a large area, while provinces with high carbon footprint have a small area. In order to determine how many provinces needed at least to solve the local regression model, Akaike Information Criterion (AICs) or Cross Validation (CV) is employed to select the adaptive number (Hu et al., 2012). Both AICs and CV will attempt to identify the best fixed distance or the best appropriate number of adjacent points of the regression province using the adaptive kernel technique (Brunsdon et al., 1996). In order to improve the computational efficiency, a big-square weighting function is selected to calculate the weight between provinces instead of Gaussian function (Brunsdon et al., 1998; Fotheringham et al., 2002). The formula is as follows:

$$
\omega_{s i}=\left(\begin{array}{ll}
{\left[1-\left(d_{s i} / d_{\max }\right)^{2}\right]^{2}} & d_{s i} \leqslant d_{\max } \\
0 & \text { otherwise }
\end{array}\right.
$$

where $d_{\max }$ is the maximum distance from the $i$ th farthest province to the regression province ( $i$ is the selected optimal neighboring provinces).

In this study, we choose both univariate and mixed GWR models to investigate the factors' separate and combined explanatory effects (Hu et al., 2012). Factors we select should have great relevance with carbon footprint. Furthermore, these factors must meet the criteria of non-collinearity and AICs minimization. Lastly, pseudo $t$ tests are selected to check the significance of estimated local parameters (Fotheringham et al., 2002).

\section{Spatial differences of carbon footprint}

\subsection{Spatial differences of the total carbon footprint in provincial China}

In this section, a "Top-Down" life cycle approach is undertaken to calculate the carbon footprint among provinces in China in 2010. Table 1 shows that there are significant differences of carbon footprint in provincial China, which is consistent with Shi's (2012) study. Total amount of carbon footprint of China is 9.72 billion tons. Provinces with the largest amount of carbon footprint are Shandong and Hebei, 655 million tons and 635 million tons respectively, followed by Jiangsu, Henan, Guangdong, Shanxi, Inner Mongolia, Liaoning and Jilin. Provinces with higher carbon footprint mainly have large economic scales, such as Shandong and Guangdong. Due to economic development, they need large amount of energy and thus have high carbon emissions. Jilin, Inner Mongolia and Shanxi have high carbon emissions, with relatively small economic scales, mainly due to low energy efficiency and high coefficient of carbon emissions. Provinces with the smallest amount of carbon footprint are Hainan and Qinghai and the carbon footprint of which is 78 million tons and 43 million tons respectively. The difference between the maximum and minimum amount of carbon footprint is 15 times. There are two types of provinces with low carbon footprint. One type is the provinces such as Qinghai and Ningxia, mainly concentrated in the Midwest, have low economic scales and low level of industrialization. Another is the provinces have relatively small energy consumption concentrating in the coastal areas, such as Hainan and Fujian. 
Table 1 Total carbon footprint and per capita carbon footprint in provincial China in 2010

\begin{tabular}{ccc||ccc}
\hline Provincial region & $\begin{array}{c}\text { Carbon } \\
\text { footprint }\left(10^{8} \mathrm{t}\right)\end{array}$ & $\begin{array}{c}\text { Per capita } \\
\text { carbon } \\
\text { footprint }(\mathrm{t})\end{array}$ & $\begin{array}{c}\text { Provincial } \\
\text { region }\end{array}$ & $\begin{array}{c}\text { Carbon footprint } \\
\left(10^{8} \mathrm{t}\right)\end{array}$ & $\begin{array}{c}\text { Per capita } \\
\text { carbon footprint } \\
(\mathrm{t})\end{array}$ \\
\hline Beijing & 2.16 & 11.01 & Henan & 5.54 & 5.89 \\
Tianjin & 1.46 & 10.28 & Hubei & 3.47 & 6.06 \\
Hebei & 6.35 & 8.84 & Hunan & 3.80 & 5.79 \\
Shanxi & 4.84 & 13.55 & Guangdong & 5.28 & 5.06 \\
Inner Mongolia & 4.77 & 19.31 & Guangxi & 2.62 & 5.69 \\
Liaoning & 4.59 & 8.49 & Hainan & 0.78 & 8.99 \\
Jilin & 4.38 & 15.95 & Chongqing & 1.55 & 5.37 \\
Heilongjiang & 3.25 & 8.48 & Sichuan & 3.46 & 4.30 \\
Shanghai & 2.36 & 10.25 & Guizhou & 2.56 & 7.37 \\
Jiangsu & 5.81 & 7.39 & Yunnan & 2.30 & 5.00 \\
Zhejiang & 3.83 & 7.04 & Shaanxi & 2.95 & 7.90 \\
Anhui & 3.06 & 5.14 & Gansu & 1.36 & 5.36 \\
Fujian & 2.03 & 5.50 & Qinghai & 0.43 & 7.64 \\
Jiangxi & 2.57 & 5.77 & Ningxia & 1.03 & 2.04 \\
Shandong & 6.55 & 6.84 & Xinjiang & 5.35 \\
\hline
\end{tabular}

From the view point of geography, provinces with high carbon footprint are mainly conentrated in northern China (Figure 1). As illustrated in Figure 1, total carbon footprint of Shandong, Hebei, Henan, Shanxi, Inner Mongolia, Liaoning, Jilin and Heilongjiang is 4.03 billion tons accounting for $41.4 \%$ of the total carbon footprint in China. Northern China with high total carbon footprint mainly associates with the enrichment of coal resources. On the one hand, the industrial structure biases towards heavy industry. On the other hand, the energy structure also depends on the coal resources, which can be converted into exporting carbon products, including electric power and coal chemical industry.

\subsection{Spatial differences of per capita carbon footprint in provincial China}

The variation in per capita carbon footprint is also very large (Table 1). Some provinces have more than 10 tons per capita carbon footprint; while in other provinces, the per capita carbon footprint is less than 5 tons. The difference is reflected by the average relative per capita carbon footprint, whose differences between the maximum and minimum is more than $60 \%$. Provinces with high per capita carbon footprint are Inner Mongolia and Ningxia, and the amount of per capita carbon footprint is 19.31 tons and 16.35 tons respectively. There are two main types' provinces with higher per capita carbon footprint. One type is Beijing, Shanghai, Tianjin and other national central cities with high level of economy resulting in high per capita carbon footprint. Another type is Inner Mongolia, Ningxia, Jilin, Shanxi and other provinces with enrichment in resources. Although the economic scale is not large, due to low energy efficiency and high carbon emission resulting high per capita carbon footprint. From the view point of geography, provinces (excluding Beijing, Shanghai and other central cities) with high per capita carbon footprint are mainly concentrated in north of China (Figure 2). Moreover, rich coal resources area and provinces with high energy-consuming industry have high per capita carbon footprint. Southern provinces have low per capita 


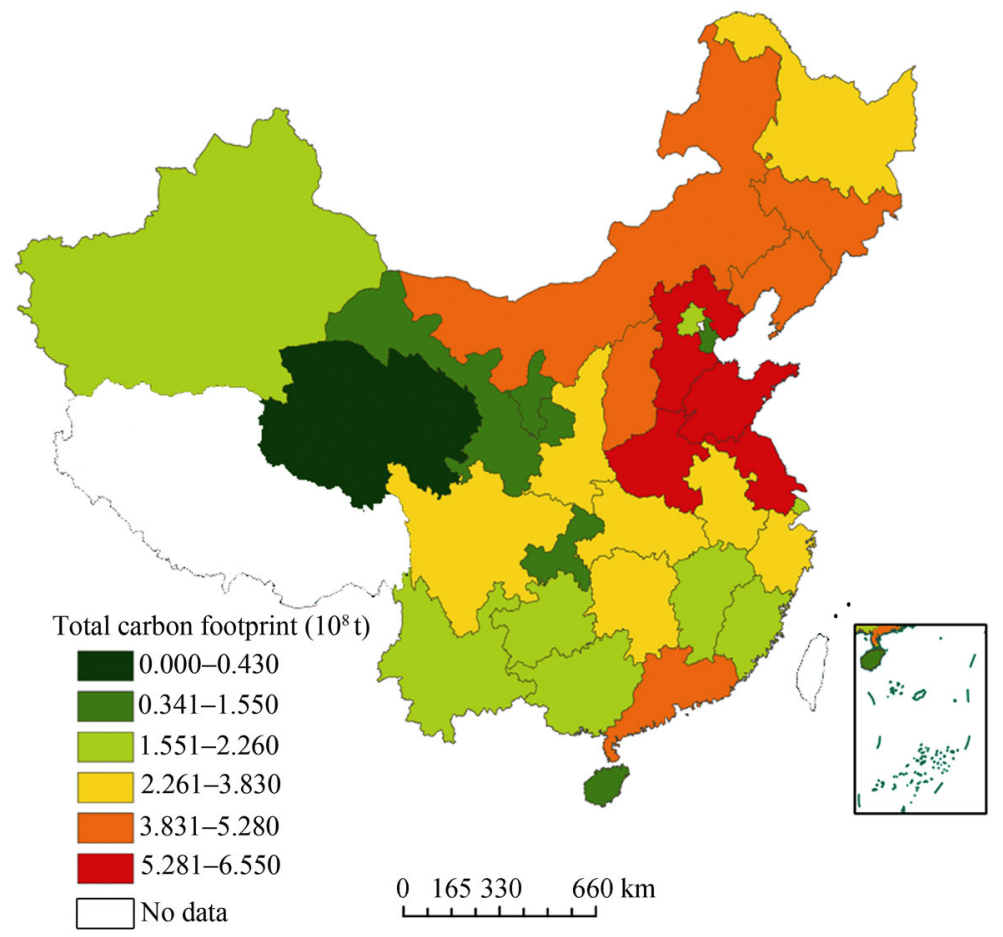

Figure 1 Spatial distribution of total carbon footprint in provincial China in 2010

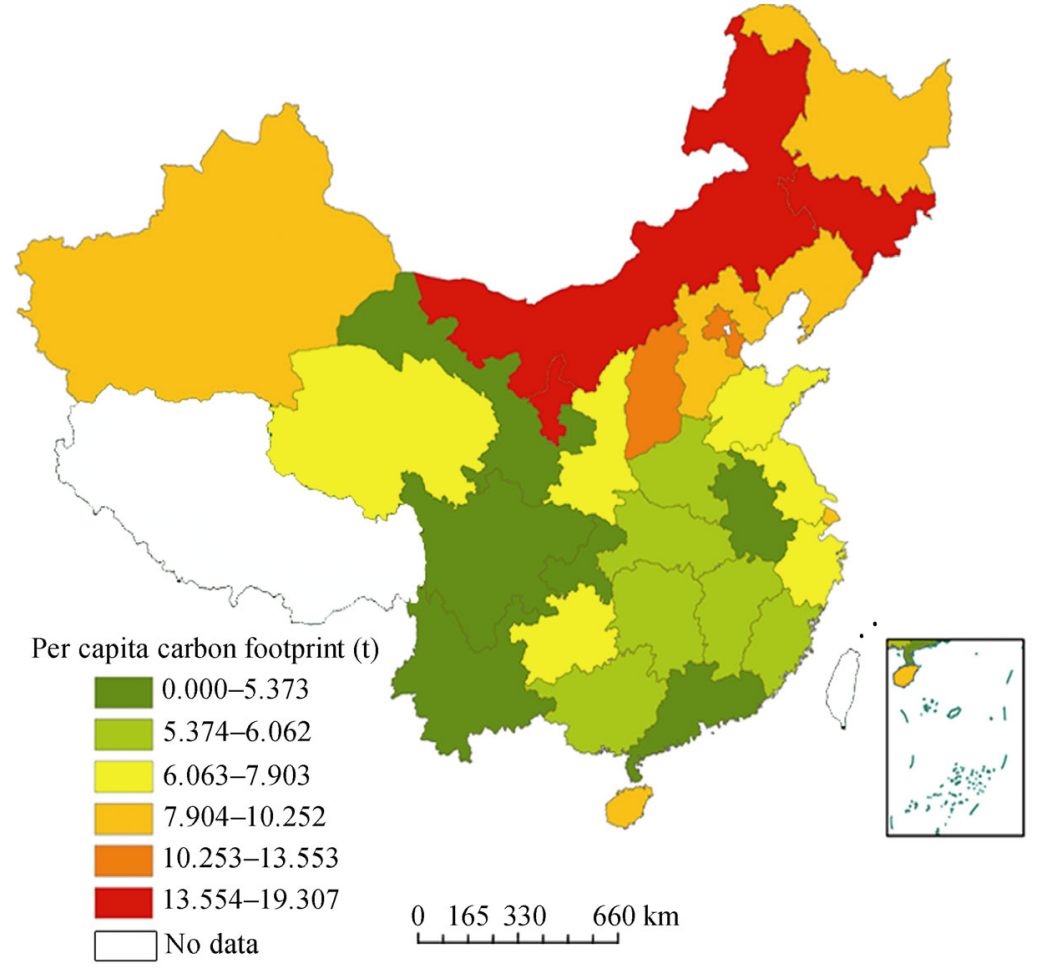

Figure 2 Spatial distribution of per capita carbon footprint in provincial China in 2010 
carbon footprint. These findings, however, might reflect the light industry structure that dominates the southern provinces in which industrialization occurs at a much faster pace than the national average. Climate varies greatly from north south. Heating in winter with less energy consumption is one of the reasons resulting in low carbon footprint due to warm climate in southern provinces.

\section{Multi-mechanism of carbon footprint}

Analyzing the influencing mechanisms of the energy carbon footprint, the first step is to find out the related factors. The research scope of the study area covers almost the whole China. Five factors varied greatly from northwest to southeast of China. Descriptive statistics of the five factors are listed in Table 2. The difference between the maximum and minimum dominant energy structure is $51.55 \%$. The corresponding difference value of $\mathrm{F}_{\text {efficiency }}$ is 0.66 t/yuan. Cities in China have different development rates, and the variation is very large. Some provinces have very high urbanization, while other provinces have relatively low urbanization. The difference between the high and low urbanization is $58.7 \%$. Due to the differences of provinces' economy and population scales, economic aggregate and population gross vary greatly between provinces, with the specific differences are $62955\left(10^{4}\right.$ yuan $)$ and $9867.33\left(10^{4}\right.$ persons $)$ respectively.

Table 2 Descriptive statistics of five factors in 2010

\begin{tabular}{cccccc}
\hline & $\begin{array}{c}\mathrm{S}_{\text {structure }} \\
(\%)\end{array}$ & $\begin{array}{c}\mathrm{F}_{\text {efficiency }} \\
\left(\mathrm{t} / 10^{4} \text { yuan }\right)\end{array}$ & $\begin{array}{c}\mathrm{U}_{\text {urbanization }} \\
(\%)\end{array}$ & $\begin{array}{c}\mathrm{R}_{\text {economy }} \\
\left(10^{4} \text { yuan }\right)\end{array}$ & $\begin{array}{c}\mathrm{P}_{\text {population }} \\
\left(10^{4} \text { persons }\right)\end{array}$ \\
\hline Minimum & 43.48 & 0.29 & 29.9 & 13119.00 & 562.67 \\
Mean & 77.57 & 0.95 & 49.82 & 33964.10 & 4432.58 \\
Maximum & 95.03 & 2.62 & 88.6 & 76074.00 & 10430.31 \\
Standard deviation & 14.75 & 0.57 & 14.29 & 17343.43 & 2707.25 \\
\hline
\end{tabular}

Note: $\mathrm{S}_{\text {structure }}$ : energy structure; $\mathrm{F}_{\text {efficiency }}$ : energy efficiency; $\mathrm{U}_{\text {urbanization }}$ : urbanization level; $\mathrm{R}_{\text {economy }}$ : economic factor; $\mathrm{P}_{\text {population: }}$ population factor

The spatial distribution of $\mathrm{S}_{\text {structure, }}, \mathrm{F}_{\text {efficiency, }} \mathrm{U}_{\text {urbanization, }} \mathrm{R}_{\text {ecomomy }}$ and $\mathrm{P}_{\text {population }}$ are displayed in Figures 3a-3e. Areas of high proportion dominant energy structure are mainly concentrated in the northern China, while high energy efficiency areas also exist in the northern part of China. Areas with higher per capita GDP are mainly distributed in central-eastern China and coastal zones. Meanwhile, population with larger scales are mainly concentrated in Henan, Shandong, Sichuan, Guangdong and Jiangsu provinces, etc.

After conducting the global analyses, the non-stationary tests of the assumed coefficients indicate that not all of the factors' coefficients are significantly varying over space. The results of the global regression analyses are shown in Table 3 (OLS model), Table 4 (spatial error model) and Table 5 (spatial lag model). The goodness-of-fit statistics, such as the AICs and log-likelihoods, indicate that the data are better fit using spatial analysis techniques. For example, AIC for the OLS model is 79.231, while for the spatial regression models they are 67.534 and 56.518 respectively; for the GWR model AIC further decreases to 48.367. Therefore, these analyses results indicate that ignoring the potential spatial factors in regres- 
sion models could reduce model effectiveness. Furthermore, the AICs also point to that the local analyses models potentially offers a better fit for the factors than global analyses (Wei et al., 2011). While in the global analysis, the Robust Lagrange Multiplier tests suggest a spatial lag instead of an error specification. Therefore, the analysis will just focus on the local regression model (GWR). And the global Moran's I index of the carbon footprint is $0.56(p<0.01)$ indicating that there is relative strong positive spatial correlation.
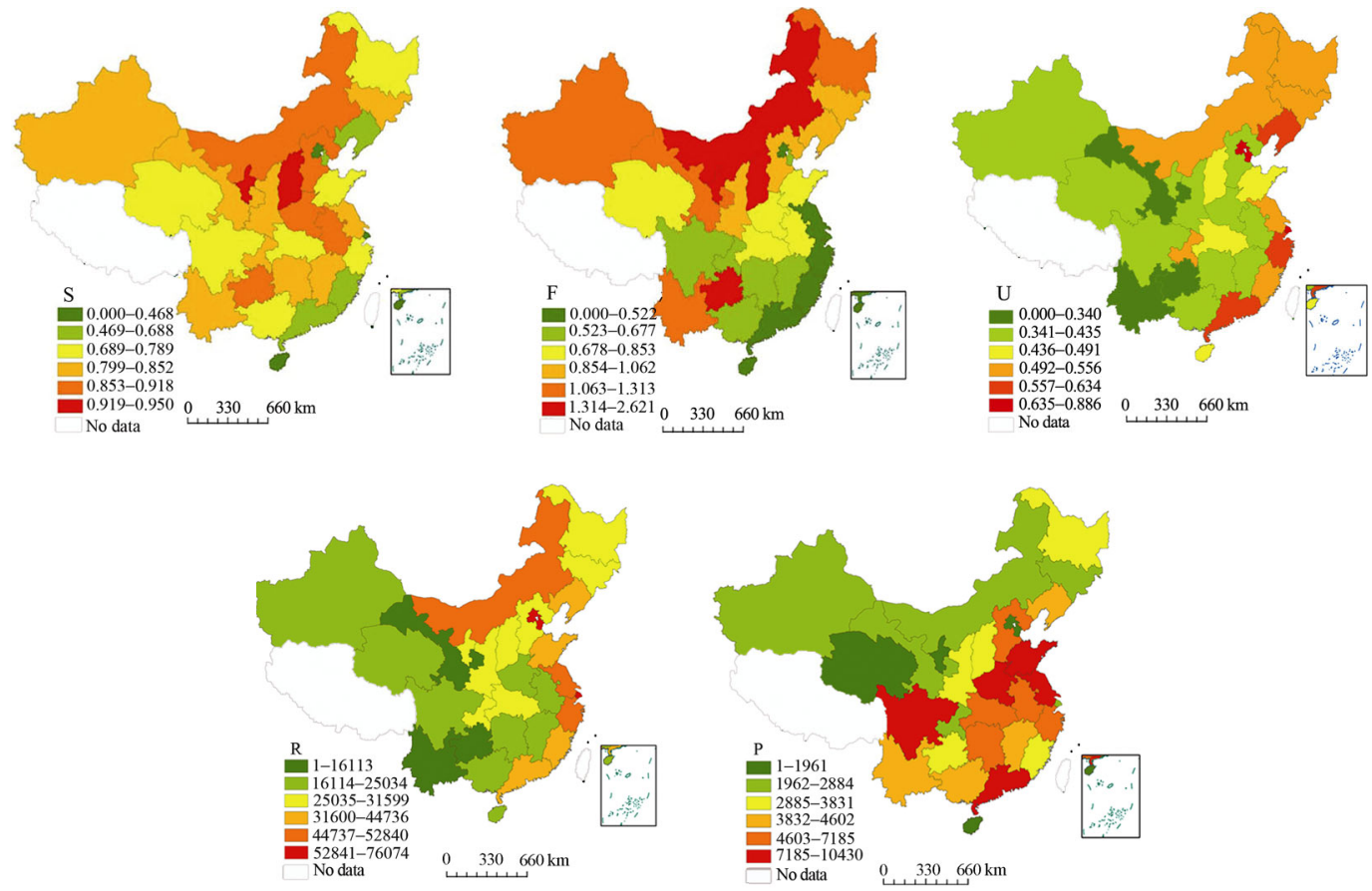

Figure 3 The spatial distribution of five potential determinants in 2010

Notes: energy structure (dominant energy share of total energy consumption), energy efficiency (per unit GDP energy consumption, $\mathrm{t} / 10^{4}$ yuan), urbanization (urban population/total population), economy factor (per capita GDP, yuan) and population factor (population size, $10^{4}$ persons)

Table 3 Global regression analyses (OLS model) in 2010

\begin{tabular}{ccccc}
\hline & \multicolumn{3}{c}{ OLS model } \\
\cline { 2 - 5 } & Coefficient & Standard error & $\mathrm{t} / \mathrm{z}$-value & $\operatorname{Pr}(>|\mathrm{t}|)$ \\
\hline CONSTANT & 0.04598533 & 0.07577884 & -0.606836 & 0.5490287 \\
$\mathrm{~S}_{\text {structure }}$ & 0.1226138 & 0.2005283 & -0.6114537 & 0.1460138 \\
$\mathrm{~F}_{\text {efficiency }}$ & -0.4224572 & 0.1843807 & 2.29122313 & 0.0299797 \\
$\mathrm{U}_{\text {urbanization }}$ & 0.0091527 & 0.1504661 & -0.0608201 & 0.0519423 \\
$\mathrm{R}_{\text {economy }}$ & 0.8650346 & 0.0990884 & 2.67472845 & 0.0125450 \\
$\mathrm{P}_{\text {population }}$ & 0.4778324 & 0.1223842 & 7.17277265 & 0.0000001 \\
\hline
\end{tabular}

Adjusted R-squared: 0.775289, F-statistic: 23.081 on 2 and 27DF, $p$-value: $5.67195 \mathrm{e}-009$

Note: $\mathrm{S}_{\text {structure }}$ : energy structure; $\mathrm{F}_{\text {efficiency }}$ : energy efficiency; $\mathrm{U}_{\text {urbanization }}$ : urbanization level; $\mathrm{R}_{\text {economy }}$ : economic factor; $\mathrm{P}_{\text {population }}$ : population factor 
Table 4 Global regression analyses (spatial error model) in 2010

\begin{tabular}{ccccc}
\hline & \multicolumn{5}{c}{ Spatial error model } \\
\cline { 2 - 5 } & Coefficient & Standard error & $\mathrm{t} / \mathrm{z}$-value & $\operatorname{Pr}(>|\mathrm{t}|)$ \\
\hline CONSTANT & 0.0153703 & 0.0589723 & -0.2606363 & 0.1943731 \\
$\mathrm{~S}_{\text {structure }}$ & 0.0038843 & 0.1456612 & 0.02666697 & 0.0787253 \\
$\mathrm{~F}_{\text {efficiency }}$ & -0.2229032 & 0.1366329 & 1.63140212 & 0.0028055 \\
U $_{\text {urbanization }}$ & 0.0069441 & 0.1119279 & 0.06204101 & 0.1505300 \\
$\mathrm{R}_{\text {economy }}$ & 0.8142238 & 0.0931959 & 1.22563354 & 0.0000000 \\
$\mathrm{P}_{\text {population }}$ & 0.4292908 & 0.0918455 & 9.02919169 & 0.0000001 \\
\hline
\end{tabular}

Lambda: 0.787422 LR test value: 8.502896, $p$-value: 0.0035458, Log likelihood: 27.077155 for error model, AIC: 67.543 (AIC for OLS: 79.231), Robust Lagrange Multiplier test: 2.5314 , on $1 \mathrm{DF}, p$-value: 0.0367

Note: $\mathrm{S}_{\text {structure: }}$ energy structure; $\mathrm{F}_{\text {efficiency }}$ : energy efficiency; $\mathrm{U}_{\text {urbanization: }}$ urbanization level; $\mathrm{R}_{\text {economy }}$ : economic factor; $\mathrm{P}_{\text {population: }}$ population factor

Table 5 Global regression analyses (spatial lag model) in 2010

\begin{tabular}{ccccc}
\hline & \multicolumn{3}{c}{ Spatial lag model } \\
\cline { 2 - 4 } & Coefficient & Standard error & $\mathrm{t} / \mathrm{z}$-value & $\operatorname{Pr}(>|\mathrm{t}|)$ \\
\hline CONSTANT & 0.06978879 & 0.0646215 & -1.079962 & 0.2801591 \\
$\mathrm{~S}_{\text {structure }}$ & 0.2301915 & 0.1820049 & -1.264755 & 0.2059594 \\
$\mathrm{~F}_{\text {efficiency }}$ & -0.4195918 & 0.1568021 & 2.675932 & 0.0074523 \\
$\mathrm{U}_{\text {urbanization }}$ & 0.0692413 & 0.1309372 & 0.528814 & 0.0969344 \\
$\mathrm{R}_{\text {economy }}$ & 0.8338999 & 0.0913506 & 1.465779 & 0.0000086 \\
$\mathrm{P}_{\text {population }}$ & 0.5362292 & 0.1035332 & 8.076922 & 0.0000000 \\
\hline
\end{tabular}

Rho: 0.287546 LR test value: 4.866677, $p$-value: 0.0273802, Log likelihood: 25.259 for lag model, AIC: 56.5181 (AIC for OLS: 79.231)

Robust Lagrange multiplier test:24.328, on $1 \mathrm{DF}, p$-value: 0.000002354

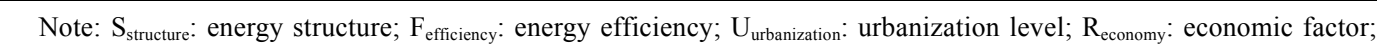
$\mathrm{P}_{\text {population: }}$ population factor

Firstly, univariate GWR models are built to test for significant relationships between the carbon footprint and each potential independent variable. The coefficients of variables for $\mathrm{U}_{\text {urbanization, }} \mathrm{S}_{\text {structure }}$ and $\mathrm{F}_{\text {efficiency }}$ are $0.56,0.62$ and 0.67 respectively (Table 6 ). The correponding values of $\mathrm{R}_{\text {economy }}$ and $\mathrm{P}_{\text {population }}$ are 0.78 and 0.82 respectively. The GWR model

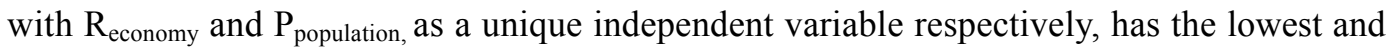
lower AIC value and the corresponding coefficients of variables among all the univariate models are relatively large. The statistical significance of the regression parameters is checked using the pseudo $t$ test. The value of provinces with significant relationship $(p<0.05)$ between carbon footprint and the independent variables are: $\mathrm{U}_{\text {urbanization }} 57.7 \%, \mathrm{~S}_{\text {structure }}$ $62.4 \%, \mathrm{~F}_{\text {efficiency }} 67.5 \%, \mathrm{R}_{\text {economy }} 77.3 \%$ and $\mathrm{P}_{\text {population }} 89.7 \%$ respectively. In provincial China, the direction of the significant relationships is not the same, even for the same variable. The values of provinces with significantly positive relationships are: $\mathrm{U}_{\text {urbanization }} 55.6 \%, \mathrm{~S}_{\text {structure }}$ $51.2 \%, \mathrm{~F}_{\text {efficiency }} 46.8 \%, \mathrm{R}_{\text {economy }} 75.6 \%$ and $\mathrm{P}_{\text {population }} 88.4 \%$ respectively. The distribution of the direction and strength of the relationships between the carbon footprint and five independent variables is displayed in Figure 4. The model residuals' global Moran's I indexes are $\mathrm{U}_{\text {urbanization }} 0.36, \mathrm{~S}_{\text {structure }} 0.24, \mathrm{~F}_{\text {efficiency }} 0.27, \mathrm{R}_{\text {economy }} 0.25, \mathrm{P}_{\text {population }} 0.29(p<0.01)$ respect- 
tively. Although each of the five independent variable residuals' spatial correlation is much smaller than the carbon footprint's spatial correlation whose Moran's I is 0.56 , the independent variables could be useful to analyze the carbon footprint's spatial variation.

Table 6 Summary of univariate GWR models for different factors in 2010

\begin{tabular}{ccccc}
\hline & $R^{2}$ & \multicolumn{3}{c}{ Significantly related provinces } \\
\cline { 3 - 5 } Factors & & $p<0.05(\%)$ & $+(\%)$ & $-(\%)$ \\
\hline $\mathrm{S}_{\text {structure }}$ & 0.62 & 62.4 & 51.2 & 7.6 \\
$\mathrm{~F}_{\text {efficiency }}$ & 0.67 & 67.5 & 46.8 & 5.9 \\
$\mathrm{U}_{\text {urbanization }}$ & 0.56 & 57.7 & 55.6 & 4.7 \\
$\mathrm{R}_{\text {ecomomy }}$ & 0.78 & 77.3 & 75.6 & 2.5 \\
$\mathrm{P}_{\text {population }}$ & 0.82 & 89.7 & 88.4 & 2.5 \\
\hline
\end{tabular}

Note: $\mathrm{S}_{\text {structure }}$ : energy structure; $\mathrm{F}_{\text {efficiency }}$ : energy efficiency; $\mathrm{U}_{\text {urbanization }}$ : urbanization level; $\mathrm{R}_{\text {economy }}$ : economic factor; $\mathrm{P}_{\text {population: }}$ population factor

Secondly, we take a further test on all the independent variables using mixed GWR model. The five independent variables are entered into the model under the criteria of non-collinearity and AIC minimization. The model's $R^{2}$ of determination is 0.87 , which is larger than each of the univariate GWR models. The statistical significance of the regression parameters is checked using the non-stationary GWR test. And all the variables are statistically significant. The global Moran's I index of the regression residual is $0.21(p<0.01)$, indicating that there is little spatial correlation. Therefore the mixed GWR model can analyze the carbon footprint's variation appropriately. The local estimated values of independent variables at provincial level are derived from the mixed GWR model (Figure 5). All of the local models are statistically significant $(p<0.05)$. Thus Table 7 gives the results of the mixed GWR models. The results of Table 7 indicate that all the determination take a positive

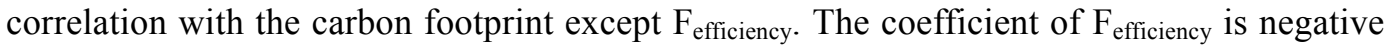
which means it is opposite to the growth of carbon footprint. Therefore, energy efficiency factor has played a positive role in reducing the amount of carbon emission. It follows that developing low carbon industries and improving the energy efficiency are the effective measures to control the carbon emission. The mixed GWR model with $\mathrm{R}_{\text {ecomomy }}$ has the largest coefficient of determination among all the five independent variables. With the capacity of fiscal capacity, local government can finance the heavy industry to promote economic growth. With the expanding of economic scale and the rapid growth of the economy, carbon footprint has been correspondingly increased. Under the background of multiples of economic aggregate expansion, a sharp rise in the level of consumption and increased energy supply and demand, large amounts of fossil energy consumption lead to the development of low carbon economy faced with the increasingly pressure. Therefore, moderately control of the scale of economy is necessary to curb the rapid growth of carbon footprint. Secondly, the results also show that population scale has exerted strong influences on the carbon footprint and it is consistently significant in both the global and local models. China has experienced a rapid growth of population since the reform and opening up under further rapid growth of economy, which is greatly attributed to the increasing of carbon footprint. 

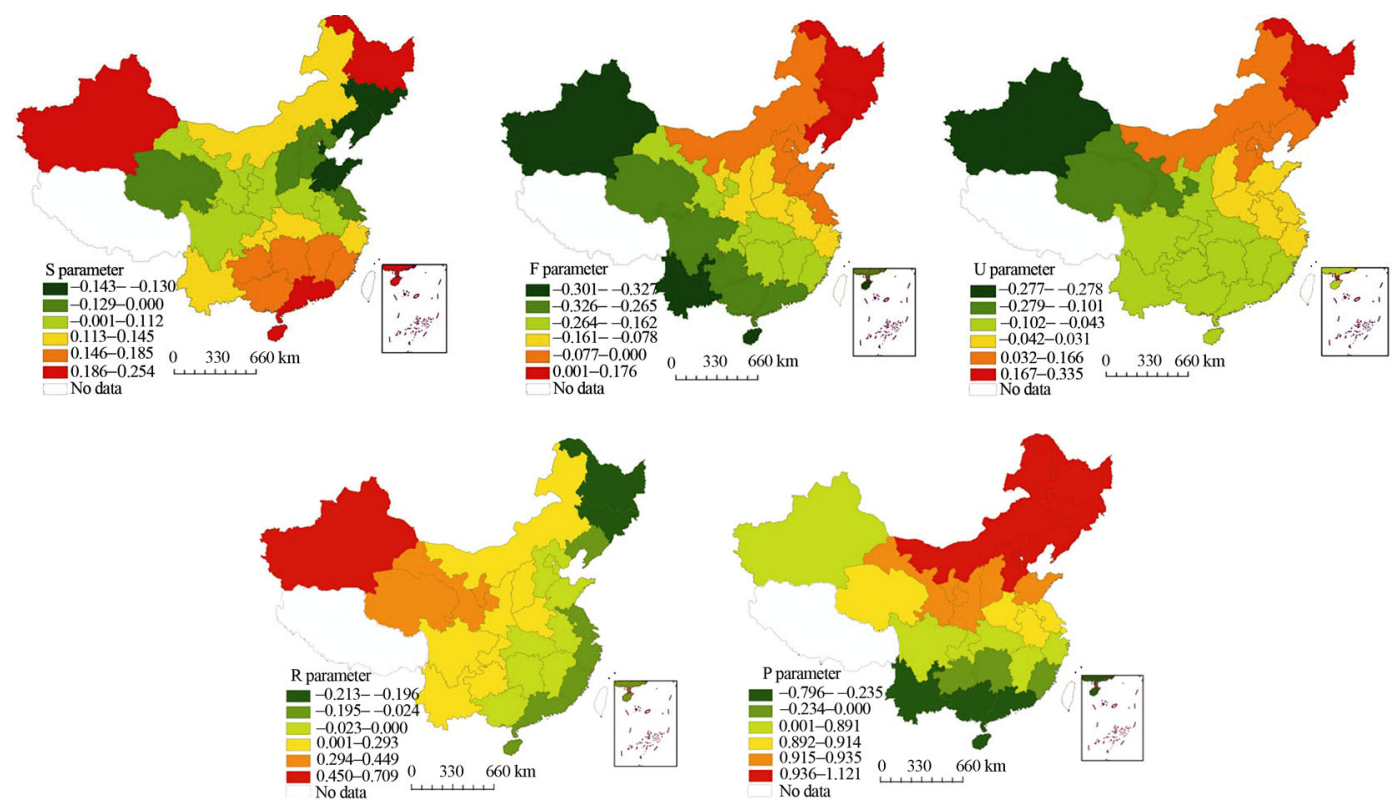

Figure 4 The spatial distribution on the local relationship between carbon footprint and five factors at provincial level in 2010

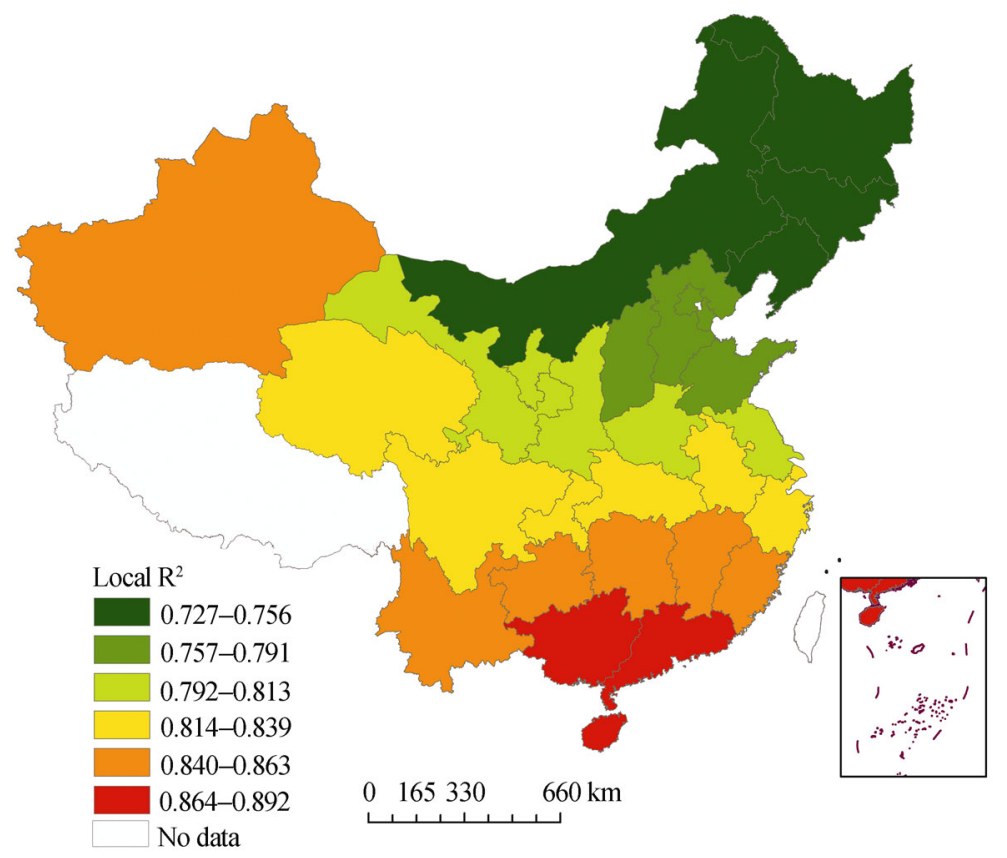

Figure 5 Local $R^{2}$ derived from mixed GWR model in 2010

These results demonstrate that the expansion of population scale plays a positive role in the growth of carbon footprint. The main effect comes from two aspects: first, population growth leads to the expansion of production by demanding. This process, however, often 
results in the greater demand in energy consumption which also reinforces the carbon footprint growth. Second, population growth leads to deforestation. Deforestation, despite its effectiveness in creating a growth oriented environment for economy, tends to have a negative impact on the control of carbon footprint and indirectly aggravates carbon emissions. Thirdly, energy structure $\left(\mathrm{S}_{\text {structure }}\right)$ promotes the growth of carbon footprint. However, in comparison with economic and population factors, energy structure has no longer been a significant factor accounting for the dominant energy changed little for a long time. Meanwhile, as shown in Table 7, reducing dependence on coal resources is helpful to reduce the carbon footprint. Lastly, urbanization, which is chosen as an indicator for the effect of cities, exhibits positive relationship with the carbon footprint. In the long term, the increase in carbon emissions will be associated with the enhancement of level of urbanization in the short term. However, there is a certain time lag in the interaction between the two. Urbanization is the cause of the carbon footprint continued to grow, but carbon footprint is not the chief reason for the urbanization growth.

Table 7 Summary of mixed GWR models for different variables in 2010

\begin{tabular}{ccccc}
\hline & \multicolumn{3}{c}{ The mixed GWR model } & \\
\cline { 2 - 5 } & Coefficient & Standard error & $\mathrm{t} / \mathrm{z}$-value & $\operatorname{Pr}(>|\mathrm{t}|)$ \\
\hline CONSTANT & 0.0956437 & 0.0446845 & 1.255213 & 0.214675 \\
$\mathrm{~S}_{\text {structure }}$ & 0.2541348 & 0.0820820 & -1.112547 & 0.064572 \\
Fefficiency & -0.6278633 & 0.2568357 & 2.364672 & 0.036743 \\
$\mathrm{U}_{\text {urbanization }}$ & 0.1859435 & 0.1409965 & 0.867456 & 0.043675 \\
$\mathrm{R}_{\text {ecomomy }}$ & 0.5726534 & 0.0613432 & 0.472894 & 0.002672 \\
$\mathrm{P}_{\text {population }}$ & 0.7435687 & 0.0035566 & 2.047683 & 0.000000
\end{tabular}

Note: $\mathrm{S}_{\text {structure }}$ : energy structure; $\mathrm{F}_{\text {efficiency }}$ : energy efficiency; $\mathrm{U}_{\text {urbanization }}$ : urbanization level; $\mathrm{R}_{\text {economy }}$ : economic factor; $\mathrm{P}_{\text {population: }}$ population factor

\section{Discussion}

Carbon footprint from energy consumption calculated in this paper is 9.72 billion tons which is much higher than that of other Chinese scholars in recent years (Table 8). This is mainly due to that there are various methods to calculate carbon footprint, and different scholars apply different methods. Based on the input-output table (IOTs), this paper concludes that carbon footprint, as a concept of carbon emissions measurement, can comprehensive evaluate life cycle carbon emissions of production, which not only includes the direct carbon emissions caused by fossil energy, but involves the embodied carbon emissions of the intermediate products' consumption in production process (Shi et al., 2012). However, in the process of calculating carbon footprint, other Chinese scholars (Wei, 2007; Liu et al., 2008; $\mathrm{Xu}, 2010$; Zhao et al., 2011; Chuai et al., 2012) only calculate the direct carbon emissions of primary energy resources, such as coal, oil, natural gas and biomass energy, not touch upon the embodied carbon emissions of the whole life cycle. Herein, Carbon footprint from energy consumption calculated in this paper is higher than others. 
Table 8 Comparison of results with other authors

\begin{tabular}{cccc}
\hline Author & Carbon footprint $\left(10^{9}\right.$ tons $)$ & Year & Reference \\
\hline Wei Baoren & 1.282 & 2005 & Wei, 2007 \\
Liu Qiang & 1.51 & 2005 & Liu et al., 2008 \\
Xu Guangyue & 1.66 & 2006 & Xu, 2010 \\
Zhao Rongqin & 1.647 & 2007 & Zhao et al., 2011 \\
Shi Minjun & 6.01 & 2007 al., 2012 \\
Chuai Xiaowei & 2.05 & 2008 & Chuai et al., 2012 \\
This paper & 9.72 & 2010 & \\
\hline
\end{tabular}

The reasons of impacting the carbon footprint are miscellaneous. In order to explore the carbon footprint and its influence mechanisms, scholars (Jiao et al., 2012; Zhou and Song, 2013; Chen, 2013; Peng and $\mathrm{Wu}, 2012$ ) begin to study carbon footprint and individual factor, such as economic growth, energy structure and energy efficiency, only by simple linear regression relationship. And significant conclusions are drawn that economic growth directly promotes the increase of the carbon footprint and improving energy efficiency can inhibit the growth of the carbon footprint. However, most studies of carbon footprint neglect that the influence mechanisms of carbon footprint are miscellaneous. A possible consequence of neglecting the multi-mechanism is the underestimation of standard errors of regression coefficients, resulting in an overestimation of statistical significance. To further understand the carbon footprint in China, geographically weighted regression (GWR) is applied to examine the multiple driving forces behind the growth of carbon footprint. We select 5 exploratory variables based on the multi-mechanism to further reveal the factors that influence carbon footprint as fully as possible. Our work draws some significant conclusions, which can help policy makers to adopt effective measures to reduce carbon emissions and its negative effects, such as global warming.

\section{Conclusions}

This paper analyzes the spatial differences and multi-mechanism of carbon footprint in provincial China and confirms the applicability of a "Top-Down" life cycle approach and GWR model framework in the empirical research on China's carbon footprint inequality at the inter-provincial level. We find that carbon footprint in China is sensitive to economic scales and industry structural changes since China's reform and opening up. By emphasizing the distinctive distributional dynamics in different provinces, this study also synthesizes its multiple driving forces for the significant differences of carbon footprint.

(1) There are significant differences of carbon footprint and per capita carbon footprint in provincial China. The provinces with higher carbon footprint, mainly concentrated in northern China, have large economic scales. Total carbon footprint of Shandong, Hebei, Henan, Shanxi, Inner Mongolia, Liaoning, Jilin and Heilongjiang is 4.03 billion tons accounting for $41.4 \%$ of the total carbon footprint in China in 2010. Northern China with high total carbon footprint mainly associates with the enrichment of coal resources. On one hand, the industrial structure biases towards heavy industry. On the other hand, the energy structure also 
depends on the coal resources, which can be converted into exporting carbon products, including electric power and coal chemical industry. The spatial distribution of the per capita carbon footprint is different from the total carbon footprint. The provinces with higher per capita carbon footprint can be divided into two types. One type is Beijing, Shanghai, Tianjin and other national central cities with high level of economy resulting in high per capita carbon footprint. Another type is Inner Mongolia, Ningxia, Jilin, Shanxi and other provinces with enrichment in resources. Although the economic scale is not large, low energy efficiency and high carbon emission cause high per capita carbon footprint.

(2) The application of spatial analysis model (GWR model) enables us to uncover that the economic scale is the primary driving force contributing to the rapid growth of carbon footprint. Added to this, the progressions of urbanization and population growth also act as the promoting factors while energy structure is marginally significant for promoting the increase of the carbon footprint. Improving energy efficiency is the most important factor to inhibit the growing carbon footprint.

(3) As China is facing great ecological pressure brought by carbon emissions, we argue that some effective measures, such as developing low-carbon economies and low-carbon industries, should be taken to reduce carbon emissions. Moreover, advocating low-carbon city construction and improving carbon efficiency would be the primary approaches to inhibit the rapid growth of carbon footprint. Moderately controlling the economy and the rapid growth of population size would also be required to alleviate the environmental pressure.

\section{References}

Brunsdon C, Fotheringham A S, Charlton M, 1996. Geographically weighted regression: A method for exploring spatial nonstationarity. Geographical Analysis, 28(4): 281-298.

Brunsdon C, Fotheringham A S, Charlton M, 1998. Spatial nonstationarity and autoregressive models. Environment and Planning A, 30(6): 957-973.

Brunsdon C, Fotheringham A S, Charlton M, 2002. Geographically weighted summary statistics: A framework for localized exploratory data analysis. Computers, Environment and Urban Systems, 26(6): 501-524.

Casler S D, Rose A, 1998. Carbon dioxide emissions in the U.S. economy: A structural decomposition analysis. Environmental and Resource Economics, 11(4): 349-363.

Chang Y F, Lin S J, 1998. Structural decomposition of industrial $\mathrm{CO}_{2}$ emission in Taiwan: An input-output approach. Energy Policy, 26(1): 5-12.

Chen Lin, 2013. A study on the factors affecting carbon emissions in China: Based on input-output model. Sino-Global Energy, 18(1): 17-22. (in Chinese)

Chuai X W, Lai L, Huang X J et al., 2012. Temporospatial changes of carbon footprint based on energy consumption in China. Journal of Geographical Sciences, 22(1): 110-124.

Druckman A, Jackson T, 2009. The carbon footprint of UK households 1990-2004: A socio-economically disaggregated, quasi-multi-regional input-output model. Ecological Economics, 68(7): 2066-2077.

Du Tingting, Mao Feng, Luo Rui, 2007. The analysis between China's economic growth and the evolution of the carbon emission. China Population, Resources and Environment, 17(2): 94-99. (in Chinese)

Duro J A, Padilla E, 2006. International Inequalities in per capita $\mathrm{CO}_{2}$ emissions: A decomposition methodology by Kaya factors. Energy Economics, 28(2): 170-187.

Fan Jie, Li Pingxing, Liang Yutian, 2010. Framework of final consumption oriented research on carbon footprints. Advances in Earth Science, 25(1): 62-70. (in Chinese)

Fotheringham A S, Brunsdon C, Charlton M, 2002. Geographically Weighted Regression: The Analysis of Spatially Varying Relationships. Chichester, UK: John Wiley and Sons. 
Gilbert A, Chakraborty J, 2010. Using geographically weighted regression for environmental justice analysis: Cumulative cancer risks from air toxics in Florida. Social Science Research, 40(1): 273-286.

Hong X, 2011. The calculation of carbon emissions of Shandong Province and the comparison with the national average. Energy Procedia, 5: 1514-1518.

$\mathrm{Hu}$ M G, Li Z J, Wang J F et al., 2012. Determinants of the incidence of hand, foot, and mouth disease in China using geographically weighted regression models. PLoS ONE, 7(6): e38978.

IPCC, 2008. Summary for Policymakers of Climate Change 2007: The Physical Science Basis. Contribution of Working Group I to the Fourth Assessment Report of the Intergovernmental Panel on Climate Change. Cambridge: Cambridge University Press.

Janssens I A, Freibauer A, Ciais P et al., 2003. Europe's terrestrial bio-sphere absorbs 7 to $12 \%$ of European anthropogenic $\mathrm{CO}_{2}$ emission. Science, 300: 1538-1542.

Jeffrey Q, Chambers, Jeremy I et al., 2007. Hurricane Katrina's carbon footprint on U.S. gulf coast forest. Science, 318(16): 1107.

Jiao Wenxian, Chen Xingpeng, Jia Zhao, 2012. Carbon footprint change of energy consumption in Gansu Province and its influencing factors. Resources Sciences, 34(3): 559-565. (in Chinese)

Kees V, Kornelis B, 1995. The direct and indirect energy requirements of households in the Nether lands. Energy Policy, 23: 893-910.

Kenny T, Gray N F, 2009. Comparative performance of six carbon footprint models for use in Ireland. Environmental Impact Assessment Review, 29(1): 1-6.

Lee K H, 2011. Integrating carbon footprint into supply chain management: The case of Hyundai Motor Company (HMC) in the automobile industry. Journal of Cleaner Production, 19(11): 1216-1223.

Lin Boqiang, Jiang Zhujun, 2009. The prediction and influencing factors analysis of environmental Kuznets curve for $\mathrm{CO}_{2}$ emissions in China. Management World, 4: 27-36. (in Chinese)

Liu Hongguang, Liu Weidong, 2009. Decomposition of energy-induced $\mathrm{CO}_{2}$ emissions in industry of China. Progress in Geography, 28(2): 285-292. (in Chinese)

Liu Hui, Cheng Shengkui, Zhang Lei, 2002. The international latest research of the impacts of human activities on carbon emissions. Progress in Geography, 21(5): 420-429. (in Chinese)

Liu Qiang, Zhuang X, Jiang K J et al., 2008. Energy and carbon embodied in main exporting goods of China. China Industrial Economy, (8): 46-55. (in Chinese)

Liu Yanhua, Ge Quansheng, He Fanneng, 2008. Countermeasures against international pressure of reducing $\mathrm{CO}_{2}$ emissions and analysis on China's potential of $\mathrm{CO}_{2}$ emission reduction. Acta Geographica Sinica, 63(7): 675-682. (in Chinese)

MacMinn C W, Juanes R, 2009. A mathematical model of the footprint of the $\mathrm{CO}_{2}$ plume during and after injection in deep saline aquifer systems. Energy Procedia, 1(1): 3429-3436.

Munoz P, Steininger K W, 2010. Austria's $\mathrm{CO}_{2}$ responsibility and the carbon content of its international trade. Ecological Economics, 69(10): 2003-2019.

Padgett J P, Steinemann A C, Clarke J H, 2008. A comparison of carbon calculators. Environmental Impact Assessment Review, 28(2/3): 106-115.

Peng Junming, Wu Renhai, 2012. Decomposition of Pearl River Delta's carbon emissions based on LMDI method. China Population, Resources and Environment, 22(2): 69-74. (in Chinese)

Piao S L, Fang J Y, Ciais P et al., 2009. The carbon balance of terrestrial ecosystems in China. Nature, 458: 1099-1014.

Piecyk M I, McKinnon A C, 2010. Forecasting the carbon footprint of road freight transport in 2020. Production Economics, 128(1): 31-42.

Pierucci S, 2009. PRES 2007: Carbon footprint and emission minimization, integration and management of energy sources, industrial application and case studies. Energy, 33: 1477-1479.

Rawski T G, 2001. What is happening to China's GDP statistics? China Economic Review, 12(4): 347-354.

Shi Minjun, Wang Yan, Zhang Zhuoying et al., 2012. Regional carbon footprint and interregional transfer of carbon emissions in China. Acta Geographica Sinica, 67(10): 1327-1338. (in Chinese) 
Shimada K, Tanaka Y, Gomi K et al., 2007. Developing a long-term local society design methodology towards a low-carbon economy: An application to Shiga Prefecture in Japan. Energy Policy, 35 (6): 4688-4703.

Soytasa U, Sari R, Ewing B T, 2007. Energy consumption, income, and carbon emissions in the United States. Ecological Economics, 62(3/4): 482-489.

Tobler W R, 1970. A computer movie simulating urban growth in the Detroit Region. Economic Geography, 46: 234-240.

Wackernagel M, Rees W, 1996. Our Ecological Footprint Reducing Human Impact on the Earth. Gabriola Island, BC: New Society Publishers.

Wang J, Liu X, Christakos G et al., 2010. Assessing local determinants of neural tube defects in the Heshun Region, Shanxi Province, China. BMC Public Health, 10: 52.

Wei Baoren, 2007. Energy Demand and Scenario Analysis of $\mathrm{CO}_{2}$ Emission in China. Beijing: China Environmental Science Press, 75. (in Chinese)

Wei Y H D, Yu D L, Cheng X J, 2011. Scale, agglomeration, and regional inequality in provincial China. Tijdschrift voor Economische en Social Geografie, 102(4): 406-425.

Wei Yiming, Liu Lancui, Fan Ying et al., 2008. China Energy Report (2008): $\mathrm{CO}_{2}$ Emissions Research. Beijing: Science Press, 31. (in Chinese)

Wiedmann T, 2009. A first empirical comparison of energy eootprints embodied in trade -MRIO versus PLUM. Ecological Economics, 68(7): 1975-1990.

Wright L, Kemp S, Williams I, 2011. 'Carbon footprinting': Towards a universally accepted definition. Carbon Management, 2(1): 61-72.

$\mathrm{Xu}$ Guangyue, 2010. The research on the relationship for energy consumption, carbon emissions and economic growth in China [D]. Wuhan: Huazhong University of Science and Technology, 64. (in Chinese)

Xu Guoquan, Liu Zeyuan, Jiang Zhaohua, 2006. Decomposition model and empirical study of carbon emission for China, 1995-2004. China Population, Resources and Environment, 16(6): 158-161. (in Chinese)

Zhang Lei, 2006. A changing pattern of regional $\mathrm{CO}_{2}$ emissions in China. Geographical Research, 25(1): 1-9. (in Chinese)

Zhang Zhuoying, Shi Minjun, 2011. Intra-industrial trade and interregional structural isomorphism of manufacturing industry based on China-IRIO 2002. Acta Geographica Sinica, 66(6): 732-740. (in Chinese)

Zhao Rongqin, Huang Xianjin, Zhong Taiyang, 2010. Research on carbon emission intensity and carbon footprint of different industrial spaces in China. Acta Geographica Sinica, 65(9): 1048-1057. (in Chinese)

Zhao Rongqin, Huang Xianjin, Zhong Taiyang et al., 2011. Carbon footprint of different industrial spaces based on energy consumption in China. Journal of Geographical Sciences, 21(2): 285-300.

Zhu Qin, Peng Xizhe, Lu Zhiming et al., 2009. Factors decomposition and empirical analysis of variations in energy carbon emission in China. Resources Science, 31(12): 2072-2079. (in Chinese)

Zou Xiuping, Song Dunjiang, 2013. Analysis on the regional gaps of the carbon emissions and its impact factors in China. Green Economy, (1): 52-55. (in Chinese) 